\title{
A morphing aerofoil with highly controllable aerodynamic performance
}

\section{DOI:}

10.1017/aer.2016.113

\section{Document Version}

Accepted author manuscript

Link to publication record in Manchester Research Explorer

\section{Citation for published version (APA):}

Wu, R., Soutis, C., Zhong, S., \& Filippone, A. (2017). A morphing aerofoil with highly controllable aerodynamic performance. Aeronautical Journal, 121(1235), 1-19. https://doi.org/10.1017/aer.2016.113

\section{Published in:}

Aeronautical Journal

\section{Citing this paper}

Please note that where the full-text provided on Manchester Research Explorer is the Author Accepted Manuscript or Proof version this may differ from the final Published version. If citing, it is advised that you check and use the publisher's definitive version.

\section{General rights}

Copyright and moral rights for the publications made accessible in the Research Explorer are retained by the authors and/or other copyright owners and it is a condition of accessing publications that users recognise and abide by the legal requirements associated with these rights.

\section{Takedown policy}

If you believe that this document breaches copyright please refer to the University of Manchester's Takedown Procedures [http://man.ac.uk/04Y6Bo] or contact uml.scholarlycommunications@manchester.ac.uk providing relevant details, so we can investigate your claim.

\section{OPEN ACCESS}




\title{
A morphing Aerofoil with Highly Controllable
}

\author{
Aerodynamic Performance
}

\section{Rui Wu' ${ }^{1}$, Costas Soutis ${ }^{2}$, Shan Zhong1, Antonio Filippone ${ }^{1}$}

1. School of Mechanical, Aerospace and Civil Engineering, University of Manchester, UK 2. The University of Manchester Aerospace Research Institute, UK

\begin{abstract}
In this paper, a morphing carbon fibre composite aerofoil concept with an active trailing edge is proposed. This aerofoil features of camber morphing with multiple degrees of freedom. The shape morphing is enabled by an innovative structure driven by an electrical actuation system that uses linear ultrasonic motors (LUSM) with compliant runners, enabling a full control of multiple degrees of freedom. The compliant runners also serve as structural components that carry the aerodynamic load and maintain a smooth skin curvature. The morphing structure with compliant truss is shown to exhibit a satisfactory flexibility and loading capacity in both numerical simulations and static loading tests. This design is capable of providing a pitching moment control independent of lift and higher L/D ratios within a wider range of angle of attack. Such multiple morphing configurations could expand the flight envelope of future unmanned aerial
\end{abstract}


vehicles. A small prototype is built to illustrate the concept but as no off-the-shelf LUSMs can be integrated into this bench top model, two servos are employed as actuators providing two controlled degrees of freedom.

Keywords: Morphing, adaptive aerofoil, multiple degrees of freedom, linear ultrasonic motor

\section{NOMENCLATURE}

$C_{D}=$ drag coefficient

$\mathrm{C}_{\mathrm{L}}=$ lift coefficient

$\mathrm{C}_{\mathrm{Lmax}}=$ maximum lift coefficient

$\mathrm{C}_{\mathrm{M}}=$ pitching moment coefficient

$\mathrm{C}_{\mathrm{P}}=$ pressure coefficient

CFRP = carbon fibre reinforced plastic

LUSM = linear ultrasonic motor

$\mathrm{FE}=$ finite element

SMA = shape memory alloy

MFC = micro fibre composite

USM = ultrasonic motor

$\mathrm{x}=$ location along chord from leading edge 


\section{INTRODUCTION}

In order to facilitate take-off and landing, and accomplish various manoeuvres, the aerodynamic forces on the wings of a flying vehicle need to be adjusted. This can be achieved by changing the camber of the wing. Conventionally, wing camber is changed using hinged control surfaces, which lead to high local surface curvature, where the flow tends to separate and causes an excessive drag. Therefore, large hinged control surfaces, such as flaps are not likely to be used on a regular basis, and this imposes constraints on the size of flight regime of the vehicle.

Wing morphing, which enables changes in aerofoil geometry while maintains a continuous and smooth aerodynamic surface, has the potential to improve aircraft performance (1-3). Among various morphing design concepts, a continuous change in camber provides a way of improving aircraft fuel efficiency and mission capability $(1,4,5)$. Wind tunnel tests have shown that by replacing a hinged flap with a morphing trailing edge, the L/D (lift/drag) ratio of a 2D aerofoil could be increased by 20\%-25\% (6,7).

The idea of morphing aerofoil was put forwarded in the 1920s and has attracted renowned interests in the recent years. However, published aerodynamic data on the performance of morphing aerofoil is still not abundant. Moreover, most researchers have focused on investigating the improvement of aerodynamic efficiency via replacing the 
hinged flap with a smooth morphing structure. In contrast, the potential of morphing aerofoils to form camber lines with different shapes, which offer multiple morphing strategies (configurations) are often overlooked.

The structural design for a morphing trailing edge is challenging since contradicting requirements, such as flexibility, load carrying capacity and lightweight, need to be satisfied $(8,9)$. Nevertheless, a few practical concepts are available. For example, the topology synthesis method can be utilised to design compliant structures that are capable of performing desired morphing under a simple actuation displacement without causing a significant strain, while satisfying other design constraints $(6,10)$. It has been reported that a morphing trailing edge designed by such a method is capable of providing $\pm 10^{\circ}$ flap deflection, $1^{\circ} /$ foot twisting along the span, and a satisfactory loading capacity (1-3). Adaptive "belt rib" concept is designed to replace the conventional ribs. It consists of a closed shell (belt) and in-plane spokes that are hinged to the shell $(1,4,5)$. Such a structure is naturally flexible and allows morphing with a single degree-of-freedom. Meanwhile, studies have shown that boundary layer can be stabilised to delay flow separation by replacing a wing's rigid upper skin in front of the conventional hinged aileron by an adaptive composite skin that is actuated along the out-of-plane direction (11-13). An array of actuators beneath the skin is used to deform the skin into different shapes optimised for various flight conditions. Similar structures can also be used on other parts of the wing and to achieve drag reduction (14-16). 
Selection of a morphing actuator that is lightweight, small in size, power efficient and fail-safe, is another challenge. A smart material actuator that can directly convert electrical, magnetic or thermal stimulation to mechanical displacement, is believed to offer a way to satisfy some of these requirements $(7,17)$. The most widely studied smart materials for actuation include shape memory alloys (SMA) and piezoelectric ceramics. However, SMA has a limited maximum strain of $8 \%$, and its 2-way shape memory effect fades out as it cycles $(8,9)$. Also, although SMA can be fast reacting, the speed of activation and deactivation relies on the heating rate and cooling conditions, which imposes a barrier to high frequency operation $(6,10)$. Furthermore, their power consumption can be increased significantly as a result of cooling (18). Piezoelectric ceramic can output large force at high speed and frequencies, and it has a power density 100 times that of SMA (19). Although the maximum strain of piezoelectric ceramic is only $\sim 0.1 \%$, they are usually used as micro fibre composite (MFC) to bend thin structures (2), and they can be an attractive option if the actuation displacement could be amplified without sacrificing the actuation force.

In this paper, a new morphing design concept is presented and it is applied to an asymmetrical aerofoil (NACA 4418). A compliant truss structure, which has multiple truss elements hinged to a compliant upper skin, forms the morphing structure. The actuators between truss elements are controlled independently to allow continuous camber change with multiple degrees of freedom. Linear ultrasonic motor is proposed as 
the morphing actuator, which is based on piezoelectric ceramics, and it can potentially provide unlimited linear output while retain the high actuation force. It also copes well with the challenge of morphing since the runners can be compliant and multi-functional to serve as the structural components. Our numerical simulations and wind tunnel tests show that besides the widely recognised benefits of morphing aerofoil over hinged control surfaces, the vehicle flight regime can be further extended by switching between different morphing strategies and allowing the pitching moment control independent of $\mathrm{C}_{\mathrm{l}}$.

\section{The proposed morphing aerofoil concept}

\subsection{Linear ultrasonic motor (LUSM)}

In a typical LUSM, pieces of piezoelectric ceramics are used to generate vibration at ultrasonic frequency and form a travelling-wave. The travelling wave can drive a body in contact with the ceramics through friction, and therefore, the high frequency displacement from the piezoelectric ceramics can be converted into a constant linear velocity. In this way, the limited actuation displacement of the piezoelectric ceramics is amplified to a theoretical infinite without necessarily sacrificing actuation, making a competitive morphing actuator possible. Also, when LUSM is powered down, the piezoelectric ceramics could inherently hold the runner and provide blocking force, 
which makes it fail-safe. However, LUSM is rarely reported being used in morphing structures.

In Table 1, three off-the-shelf LUSMs are set in comparison with revolving ultrasonic motors (USM) and electric motors that are reported in literature (20). In terms of power density, which is a critical parameter for morphing actuators, LUSM is not attractive. However, the main reason for this drawback is that LUSM is currently developed as a positioning device due to its intrinsic fast response and high open-loop precision, rather than a heavy-duty actuator. There is a significant room for further improvements, such as in weight reduction and power enhancement. It has been reported that the power of ultrasonic motors could be increased for instance by fine-tuning the driver frequency $(19,20)$.

Meanwhile, DC motors usually need transmission mechanism to reduce the speed, which significantly decreases power density. For example, the power density of DC motor in Table 1 is reduced from $235 \mathrm{~W} / \mathrm{kg}$ to $27 \mathrm{~W} / \mathrm{kg}$ when a harmonic gear transmission system is used (20). This will also lead to an increased space occupation and a reduced reliability.

Therefore, LUSM has the potential to be a future morphing actuator solution, especially when space is strictly limited, such as in mini unmanned aerial vehicles (MUAV), or when a large number of actuator is needed to control numerous degrees of freedom. 
Table 1. Actuator comparisons (20)

\begin{tabular}{|c|c|c|c|c|c|}
\hline Actuator & $\begin{array}{l}\text { Output } \\
\text { force/torque }\end{array}$ & $\begin{array}{l}\text { Holding } \\
\text { force }\end{array}$ & Velocity & $\begin{array}{l}\text { Weight } \\
\text { (g) }\end{array}$ & $\begin{array}{l}\text { Power density } \\
(\mathrm{W} / \mathrm{kg})\end{array}$ \\
\hline N216 NEXTLINE ${ }^{\circledR}$ (LUSM) & $60 \mathrm{~kg}$ & $80 \mathrm{~kg}$ & $1 \mathrm{~mm} / \mathrm{s}$ & 1250 & 0.48 \\
\hline N422 Linear Actuator (LUSM) & $0.7 \mathrm{~kg}$ & $1 \mathrm{~kg}$ & $5 \mathrm{~mm} / \mathrm{s}$ & 25 & 1.4 \\
\hline U-264 RodDrive OEM (LUSM) & $0.3 \mathrm{~kg}$ & $1.5 \mathrm{~kg}$ & $200 \mathrm{~mm} / \mathrm{s}$ & 80 & 7.5 \\
\hline SPL-801 (USM) (20) & $10 \mathrm{~kg} \mathrm{~cm}$ & $\mathrm{~N} / \mathrm{A}$ & $210 \mathrm{rpm}$ & 249 & 95 \\
\hline Maxon DC motor (brushless) (20) & $0.076 \mathrm{~kg} \mathrm{~cm}$ & - & $25,000 \mathrm{rpm}$ & 86 & 235 \\
\hline Harmonic gear with DC motor (20) & $32 \mathrm{~kg} \mathrm{~cm}$ & $\mathrm{~N} / \mathrm{A}$ & $60 \mathrm{rpm}$ & 739 & 27 \\
\hline
\end{tabular}

\subsection{The proposed concept: compliant runners driven by LUSM}

The LUSM requires a compliant runner that can provide effective contact with the piezoelectric actuator. Keeping this in mind, an actuation system with multifunctional compliant runners driven by LUSMs is proposed, as shown in Figure 1. Since a homogeneous compliant runner naturally maintains a smooth curvature under bending, and it is able to provide out-of-plane stiffness and axial stability, it is an ideal actuator for a morphing wing, in which a smooth aerodynamic surface, structural compliance and loading capacity are required. 


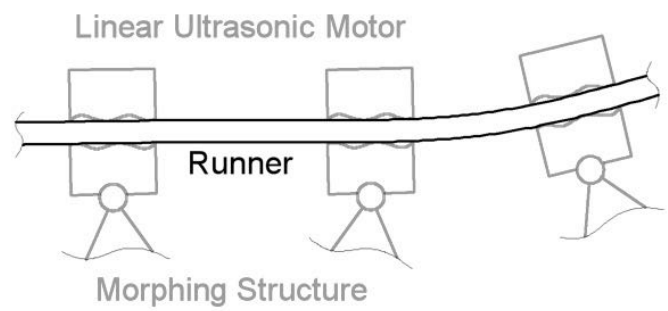

Figure 1. Schematic view of the actuation system concept with a compliant runner and LUSMs, where LUSMs are pivoted onto the actuated morphing structure and the runner naturally forms a smooth curvature.

As shown in Figure 1, multiple LUSMs pivoted to a morphing structure with multiple degrees of freedom could run along the same runner. Therefore, all the degrees of freedom can be controlled, and a smooth curvature can be formed. Such an actuation system can be integrated into various morphing structures as a universal actuator solution.

When used on the surface of morphing wing, it is necessary for it to be airtight. This can be achieved by applying morphing skins, such as segmented compliant panels or elastomers, which can passively slide along the runner.

Also, besides the actuation and the structural capacity, more functionality can potentially be embedded into the runner due to its unique position. For example, sensors, such as optical fibres, can be used to monitor the curvature of the runner, and electronics can be embedded in the runner hence converting it into a data link between the controller and a large number of actuators. 


\subsection{The Morphing Structure}

In the morphing aerofoil, the actuation system needs to be supported by a morphing structure that can change shape under actuation, provide loading capacity by eliminating the unwanted degrees of freedom, and form the aerodynamic profile. In this research, the baseline NACA 4418 aerofoil was selected because of its relatively high thickness and near-flat lower surface, which makes it easier to manufacture and implement the morphing actuation system.

A carbon fibre composite morphing structure with compliant truss is proposed. As shown by Figure 2, the morphing aerofoil consists of a rigid wing box (which ends at $40 \%$ chord), a flexible upper skin, four independent compliant truss elements and a rigid trailing edge. The actuation system is used as the lower skin of the aerofoil. The LUSMs are positioned at the bottom apex of truss elements, which are hinged to the upper skin. One or more runners are fixed to the trailing edge and slide through the LUSMs as described in $§ 2.2$. The truss elements shown in Figure 2 have a span-wise shift to prevent interference with neighbouring trusses with a lower vertex angle between trusses of $60^{\circ}$. This is a compromise between overall structural stiffness and the number of truss elements; it also reduces the thickness mismatch between the rigid wing box and the morphing section under large deflection. The number of actuators is equal to the number of truss elements, spaced equally 
along the runner.

When the truss elements are sliding along the runner, the morphing structure will bend or straighten and the camber of aerofoil will change.. During morphing, the flexible composite upper skin and the runners on lower skin will maintain smooth curvature that guarantees aerodynamic efficiency. The truss elements will also undergo small elastic deformation that can be accommodated by their compliance.

A major advantage of this morphing structure is that it can morph with multiple degrees of freedom and thus provides a wide range of camber line shapes, which is enabled by the independent actuation of the four truss elements as well as the rigid trailing edge by the five sets of LUSMs. Meanwhile, the CFRP truss structure naturally possesses high specific stiffness and strength, and provides adequate loading capacity. For the same reason, low bending stiffness of the structural elements is allowed, which leads to low resistance to camber morphing.

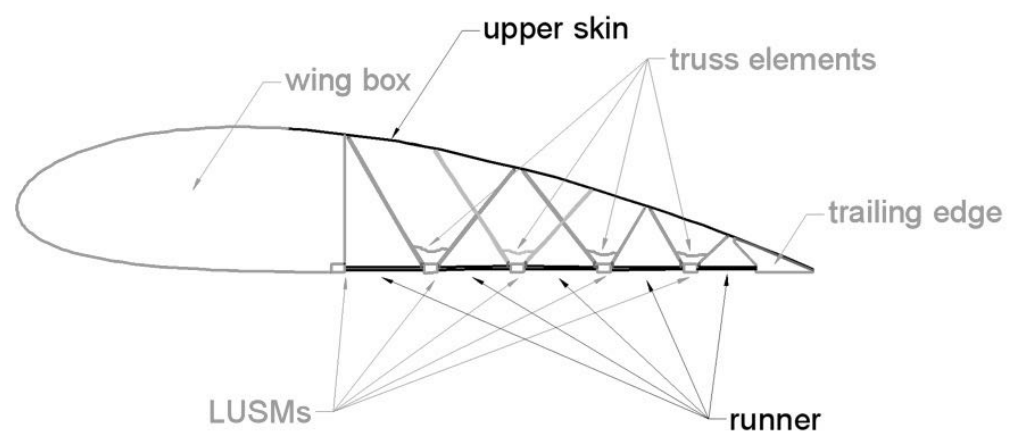

Figure 2. Schematic view of the morphing aerofoil concept with the compliant truss configuration and the proposed LUSM actuation system. The system provides 5 degrees of freedom. 


\subsection{Simulation of Morphing Process}

A nonlinear FE simulation is carried out to show the morphing process of the proposed aerofoil and to assist later analysis.

A 3D model of the morphing aerofoil is constructed with a $280 \mathrm{~mm}$ chord and $5 \mathrm{~mm}$ span. All materials are assumed to be linear, elastic and isotropic. The upper carbon fibre reinforced plastic (CFRP) skin is $0.25 \mathrm{~mm}$ thick $\left(\mathrm{E}=100 \mathrm{GPa}, \rho=1.6 \mathrm{~g} / \mathrm{cm}^{3}\right)$, the trusses are made of $0.5 \mathrm{~mm}$ thick CFRP plate, the lower joints of trusses are plywood $(\mathrm{E}=800 \mathrm{MPa}$, $\left.\rho=0.7 \mathrm{~g} / \mathrm{cm}^{3}\right)$, the runners are CFRP rods of $1 \mathrm{~mm}$ diameter $\left(\mathrm{E}=100 \mathrm{GPa}, \rho=1.6 \mathrm{~g} / \mathrm{cm}^{3}\right)$, and the LUSM are replaced by CFRP plates. The lower morphing skin is not included since it should not have significant effect on the morphing process. The model has the same material properties and dimensions to the prototypes discussed in $\S 5$, except that it is a near 2D model with $5 \mathrm{~mm}$ span and only one runner is included.

In the analysis the hinges between truss and upper skin are assumed to provide no bending resistance. Sections of runners are fixed between adjacent actuators, and actuation is represented by thermal contraction/expansion of the runners. This does not resemble the interface between the piezoelectric ceramic and the runner, but it fully replicates the conditions of the morphing structure under actuation (while ignoring small change of the runner's diameter), and significantly saves computational time. The 
thermal contraction of different sections of runners can be controlled independently, so all of the 5 degrees of freedom can be manipulated.

The structural weight (excluding wing box) from the simulation is 22 grams, which is equivalent to 440 grams per meter span, and the morphed shape, as shown in Figure 3, is smooth. However, slight waviness can be seen in the upper and lower skins, which is captured in both the analysis models and wind tunnel test models. According to literature (21), lift and drag are barely influenced by an upper surface protuberance located after the middle chord with a height of up to $0.5 \%$ chord length, thus this waviness is expected to have minor effect on the morphed aerofoil's performance. More morphing configurations are shown in $\S 3$.

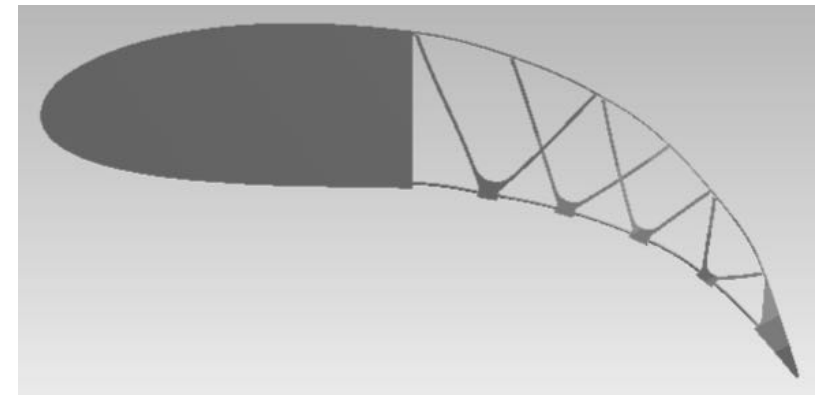

Figure 3. Finite-element simulation illustrating a morphing configuration with near-maximum trailing edge deflection.

\subsection{Numerical Simulation of Loading Capacity}

Achieving sufficient load carrying capacity is an additional objective of morphing aerofoil design. As a preliminary assessment, a nonlinear static FE simulation is carried out to test 
the model aerofoil's loading capacity.

The model has the same material properties and dimensions to the one used in $\S 2.4$, except that the span is $50 \mathrm{~mm}$, and 10 rods with $5 \mathrm{~mm}$ spacing are included, making it identical to the static prototype discussed in $§ 5$. The aerodynamic load is assessed with the 2D Xfoil code, see $\S 3$, then the load distribution on both sides of the aerofoil is integrated into 6 forces evenly distributed within 6 adjacent regions on the lower surface of the morphing part, and then the forces are applied to the same regions of the 3D structural model. The 6 regions are divided by the actuators and trailing edge, as shown by Figure 4. This loading condition is identical to the static loading test on the prototype built in section 4 . There is no direct load on the upper surface since the aim here is to evaluate the load carrying capacity of the truss structure, while the behaviour of the upper skin can be modified as needed if bigger models were constructed; the objective is to illustrate the morphing concept and demonstrate in a small physical model.

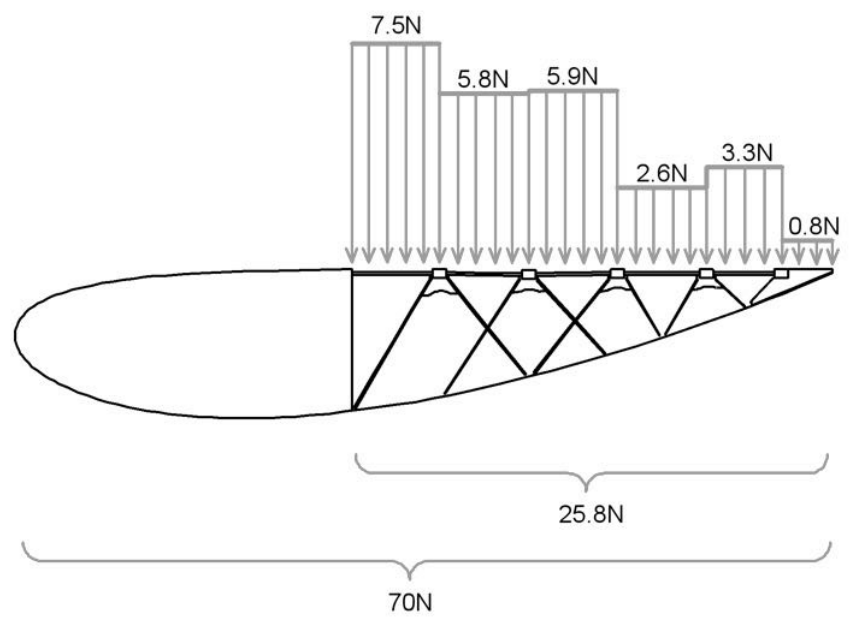

Figure 4. Chordwise load distribution used in the static load simulation with an overall load of 70 
N.

Three different loading conditions with the whole aerofoil carrying $70 \mathrm{~N}, 130 \mathrm{~N}$ and 250 $\mathrm{N}$ load are simulated. No large deformation is observed, and the results are listed in Table 2, where both the maximum deflection across the aerofoil and the deflection of trailing edge are reported, and the ratio of maximum deflection in chord length is also reported to show the extent of deformation. Three equivalent flight conditions are included in Table 2 to provide an idea about the possible flight regime. It should be noted, the load here represents the overall load across the whole aerofoil, and the morphing part only carries $26 \mathrm{~N}, 48 \mathrm{~N}$ and $93 \mathrm{~N}$ load respectively, since most of the aerodynamic force is generated near the leading edge.

Table 2. Results of the static structural simulation

\begin{tabular}{c|c|c|c|c}
\hline Load (N) & Deflection (mm) & Def./chord & Equivalent condition & Note \\
\hline 70 & $0.36(0.2$ at TE) & $0.13 \%$ & $C_{l}=0.8, \mathrm{v}=80 \mathrm{~m} / \mathrm{s}, \mathrm{SF}=1.5$ & Baseline AoA $=3.6^{\circ}$ \\
\hline 130 & $0.56(0.3$ at TE) & $0.2 \%$ & $C_{l}=1.5, \mathrm{v}=80 \mathrm{~m} / \mathrm{s}, \mathrm{SF}=1.5$ & Baseline max. lift \\
\hline 250 & $1.17(0.5$ at TE) & $0.42 \%$ & $C_{l}=1.5, \mathrm{v}=111 \mathrm{~m} / \mathrm{s}, \mathrm{SF}=1.5$ & Baseline max. lift \\
\hline
\end{tabular}

$\mathrm{SF}=$ safety factor, which is applied to force; $\mathrm{TE}=$ trailing edge; AoA = angle of attack 


\section{Aerodynamic Performance}

Unlike conventional hinged flap, the morphing aerofoil always maintains a smooth surface, and it can be controlled with multiple degrees of freedom. In order to investigate the aerodynamic impact of these features, aerodynamic analysis and wind tunnel tests are carried out to evaluate the performance of aerofoil (with a baseline profile of NACA 4418) at different morphing configurations and flight conditions (different angles of attack).

\subsection{Morphing Strategies}

The multiple degrees of freedom of the proposed morphing aerofoil can be used to generate different morphing configurations. This can be done by controlling the five sets of LUSMs independently in reality, or assigning the thermal expansion of the five rods independently in the structural simulation (as discussed in §2.4).

The morphing leads to camber change, and multiple actuators along the chord can alter the curvature of camber line at different chord-wise locations. At a constant trailing edge deflection, different morphing settings yield aerofoils with different camber lines shapes (Figure 5). There is an infinite number of possible morphing shapes; for an aerofoil with camber increased at one location, that location can be continuously moved along the chord by adjusting the output of different sets of actuators. As shown in Figure 5, two intuitively defined morphing strategies and a conventional hinged flap are considered: 
- Strategy 1: Morphing aerofoil with camber intensively changed near the maximum thickness and an unchanged trailing edge;

- Strategy 2: Morphing aerofoil with camber intensively changed near trailing edge;

- Strategy 0: Aerofoil with a hinged flap at 0.75 chord length.

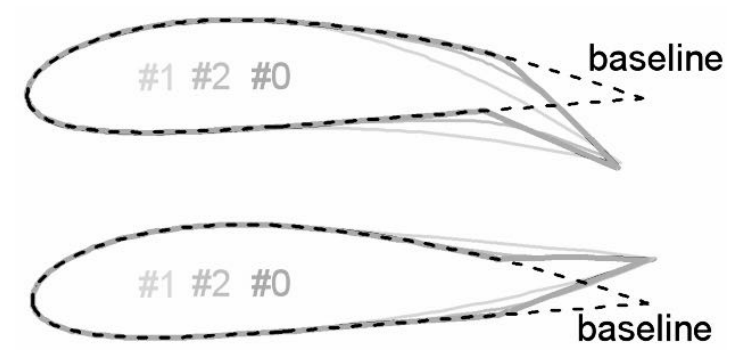

Figure 5. 2D aerofoil models at $0^{\circ}$ angle of attack with three different morphing strategies.

The 2D aerofoils shapes for aerodynamic analysis are generated using the 3D models resulted from the structural simulations. In the structural simulations, the ratio between the amounts of runner expansion is kept constant for each morphing strategy to realise different trailing edge deflection with a similar camber line shape.

\subsection{Aerodynamic Analysis Setup}

\subsubsection{Xfoil Analysis}

Xfoil is a code widely used in research to analyse the flow around a subsonic aerofoil. It is based on a revised 2D panel method that takes into account of the viscosity and 
compressibility effects, allowing reasonable predictions of lift, drag and pitching moment, as well as flow separation point beyond the stall angle $(22,23)$. In literature (24), a morphing wing with adaptive upper skin has been tested in wind tunnel at Reynolds numbers similar to the present research. The tests use fourteen to sixteen pressure taps to measure the pressure distribution on the aerofoil, the results are then used to determine the location of flow transition. The comparison to Xfoil analysis has shown a close agreement on surface pressure coefficients and transition occurrence.

The computational analysis discussed in the following sections is performed with Xfoil at Reynolds number $R e=1.5 \cdot 10^{6}$ (based on the aerofoil chord length) and Mach number $M=0.235$. This is representative of a $28 \mathrm{~cm}$ chord length mini UAV flying at sea level. An analysis with $R e=0.5 \cdot 10^{6}$ and $M=0.078$ is carried out to match the condition of wind tunnel tests.

\subsubsection{Wind Tunnel Tests}

To support the simulations, wind tunnel tests have been performed at a free-stream velocity of $25 \mathrm{~m} / \mathrm{s}$ and the Reynolds number $R e=0.5 \cdot 10^{6}$. Using multiple rigid models, seven different aerofoil morphing states are tested, including: baseline (strategy 0 with 0 mm deflection), strategies 0,1 and 2 with $30 \mathrm{~mm}$ downward and $20 \mathrm{~mm}$ upward deflection. 


\subsubsection{Model Construction}

Rigid models with a $280 \mathrm{~mm}$ chord (same as in aerodynamic analysis) and a $600 \mathrm{~mm}$ span and cross-sections representing different morphing states are made by laying up glass fibre cloth with epoxy onto a reinforced foam core, forming a skin of $\sim 0.5 \mathrm{~mm}$ thickness. The foam core is shaped by a CNC hot-wire cutting machine with the tolerance of around $0.5 \mathrm{~mm}$ due to material burn-off. All the models are polished with P180 sand papers to give a fairly smooth surface finish.

The hinged aerofoil model has a movable flap, which is attached to the fore body via three hinges along the span. The flap has a circular leading edge that can just fit into the concave slot in the rare part of the fore body to eliminate all gaps between the fore body and the flap. This ensures the aerofoil surface to be as smooth as possible (with fluctuation height near the junction $<1 \mathrm{~mm}$ ) and no air can escape from the lower surface to the upper surface.

\subsubsection{Wind Tunnel Setup}

The aerofoil is tested in the Project tunnel at University of Manchester. The tunnel has an octagonal test section measuring $87 \mathrm{~cm} \times 111 \mathrm{~cm}$ (height $\times$ breadth). To ensure a 2D flow around the aerofoil, the aerofoil model is mounted between the two splitter plates spanning across the whole width of the test section. The function of splitter plates is to isolate the tips of aerofoil models from the tunnel wall boundary layers and to ensure a 
near 2D aerodynamic behaviour. A $2 \mathrm{~mm}$ gap is left between the splitter and each end of the aerofoil for clearance. The aerofoil model is mounted to a six-component load balance through a sting, which passes through a hole in the upper splitter plate.

The speed measured at the original test section inlet cannot be used since the complicated blockage effect caused by the splitter plates, test model and tunnel wall will alter the flow velocity between the splitters (25). The free stream speed is determined instead with a Pitot tube located between the splitters at $11 \mathrm{~cm}$ away from the sidewall and $60 \mathrm{~cm}$ upstream of the aerofoil leading edge.

The test points are recorded by a computer program that averages the data sampled at 1 $\mathrm{kHz}$ during a second. To further reduce the fluctuation, each data points reported in this paper is the average of five repeated tests.

The maximum total blockage effect, including the contribution of solid blockage and wake blockage, is lower than 3.5\%. All the test data reported in this paper have been corrected for blockage effect and lift effect, as well as circulation effect that account for a change up to $7 \%$ in the measured dynamic pressure due to proximity of the Pitot tube to the aerofoil model $(25,26)$. 


\subsection{Aerodynamic Results}

\subsubsection{Results on Aerofoils with an Increased Camber}

Before moving on to a detailed discussion of the result, it is worth explaining the function of the layout of Figure 7 and 8. Each of these figures has set three subplots in comparison. The subplots represent the results from Xfoil analysis at two different Reynolds numbers and the wind tunnel test, respectively. Figure 7 (a) shows the results at $R e=1.5 \cdot 10^{6}$, which is representative of a UAV. The key results can be derived from this figure, but it still requires experimental validation. Figure 7 (b) shows the results from the wind tunnel tests, which are carried out at a lower Reynolds number of $0.5 \cdot 10^{6}$, due to the constraint of test models and equipment; this included only one deflection, due to the time limitation. However, it is sufficient to support the analysis results if the Reynolds number effect is not significant. Therefore, Figure 7 (c) is plotted, which shows the analysis results at the test Reynolds number. By comparing it to (b), it can be seen that the curves from the test and the analysis results show very similar trends despite the difference in magnitudes that is discussed later. The comparison between (c) and (a) shows that the Reynolds number effect has causes no significant change in the trend of the curves. Therefore, the trend of the curves shown by Figure 7 (a) is supported by experimental results (and similar for Figure 8 (a) and for the results discussed in §3.3.2), and the key conclusions on the effects of different morphing strategies can be made. 
The difference in the results' magnitudes is mostly caused by the way that lift and drag are measured, which includes the test model's 3D effects. In Figure 6, lift and drag results of the baseline aerofoil NACA 4418 from the wind tunnel test, Xfoil analysis and NACA Langley wind tunnel (27) are compared. As shown in the figure, the analysis shows good agreement with NACA test results, but the test results in the presented research shows differences. For instance, within an angle of attack range of $3^{\circ} \sim 5^{\circ}$, the $C_{D}$ is approximately 0.02 greater and $\mathrm{C}_{\mathrm{L}}$ is around 0.2 lower.

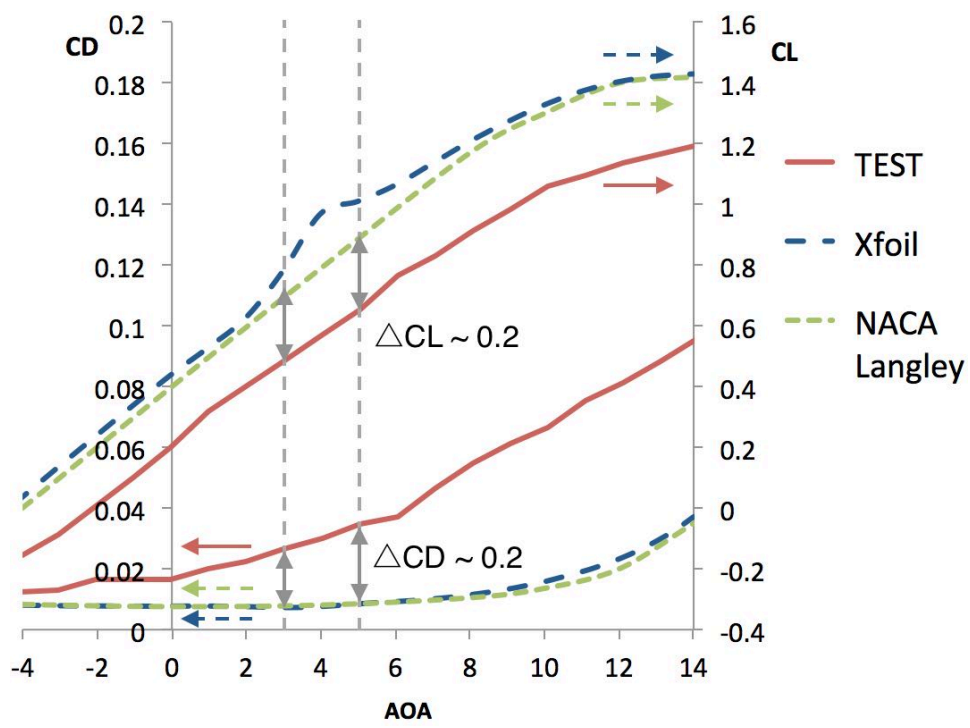

Figure 6. Comparisons between lift and drag coefficient of the baseline NACA 4418 aerofoil from the present wind tunnel test $\left(R e=0.5 \cdot 10^{6}\right)$, Xfoil analysis $\left(R e=0.5 \cdot 10^{6}\right)$ and NACA Langley wind tunnel test $\left(R e=3 \cdot 10^{6}\right)(27)$.

In the NACA test, the lift is deduced from the pressure distributions measured on the aerofoil surfaces, and the drag is evaluated from the pressure in the wake (27). Such methods allow the measuring devices to be placed near the centre of wingspan (28), and hence the 3D effect can be significantly reduced. Whereas in the present wind tunnel test, 
all the forces are measured directly with the force balance and the forces on the wing tips are included. The mechanical clearance between the wingtips and splitters causes 3D effects that increase drag and reduce lift that leads to the difference in the results.

To briefly summarise the observations from the results, when the morphing strategy changes from strategy 1 to 2 and finally to strategy 0 , which is the aerofoil with a hinged flap, the location of maximum camber increment moves towards the trailing edge and the maximum curvature of the camber line increases. It is shown by the results that when such changes are made, the aerofoil tends to be more efficient (higher L/D) at higher angles of attack and less efficient (lower L/D) at lower angles of attack.

In Figure 7, L/D ratio is plotted against $C_{\mathrm{L}}$, which shows that at each trailing edge deflection, the morphing strategy 1 yields the highest L/D ratio among the three configurations within the lower range of $C_{L}$ tested, but its $L / D$ drops more rapidy than other strategies at higher $\mathrm{C}_{\mathrm{L}}$, which is obviously associated with a rapid increase in $\mathrm{C}_{\mathrm{D}}$. It can be seen in the figure that $C_{L}$ can be increased by increasing trailing edge deflection. Morphing strategy 1 is the most efficient until $\mathrm{C}_{\mathrm{L}}$ is over $\approx 1.7$ with a maximum trailing edge delfection of $30 \mathrm{~mm}$. Morphing trategy 2 gives the highest $\mathrm{L} / \mathrm{D}$ ratio until $\mathrm{C}_{\mathrm{L}} \approx 1.8$. At higher $C_{L}$ values, strategy 0 , is the better performing morphing configuration.

As shown in Figure 8, where $C_{\mathrm{L}}$ is plotted against angle of attack, strategy 1 starts to stall and lose lift earlier (at $\sim 3^{\circ}$ angle of attack), which suggests that strategy 1 can only be 
advantageous at low angles of attack. The maximum $\mathrm{C}_{\mathrm{L}}$ that can be achieved by the three strategies while keeping $C_{D}$ below a certain value is presented in Figure 9. The baseline NACA 4418 is also plotted as a reference without the $C_{D}$ constraint ( $C_{D}$ varies), It can be seen that as the angle of attack increases, or as the maximum attainable lift increases (at the expense of drag), the most efficient strategy changes from strategy 1 to 2 , and finally to strategy 0 (hinged flap) when a very low L/D ratio is obtained. It is a sequence in which the location of maximum camber increment approaches trailing edge and the maximum camber line curvature increases. The curves in Figure 9 are rather zigzagged since the data points are generated from discrete data with seven trailing edge deflection values and three strategies.

The morphing aerofoils outperform the baseline, while the improvements in efficiency over hinged flaps at relatively high angles of attack (see Figure 9) are not as significant as some previous studies have suggested. This may be because the hinged aerofoil used in the wind tunnel tests of this research has been made as smooth as possible and the junction between wing and flap has been made airtight. 

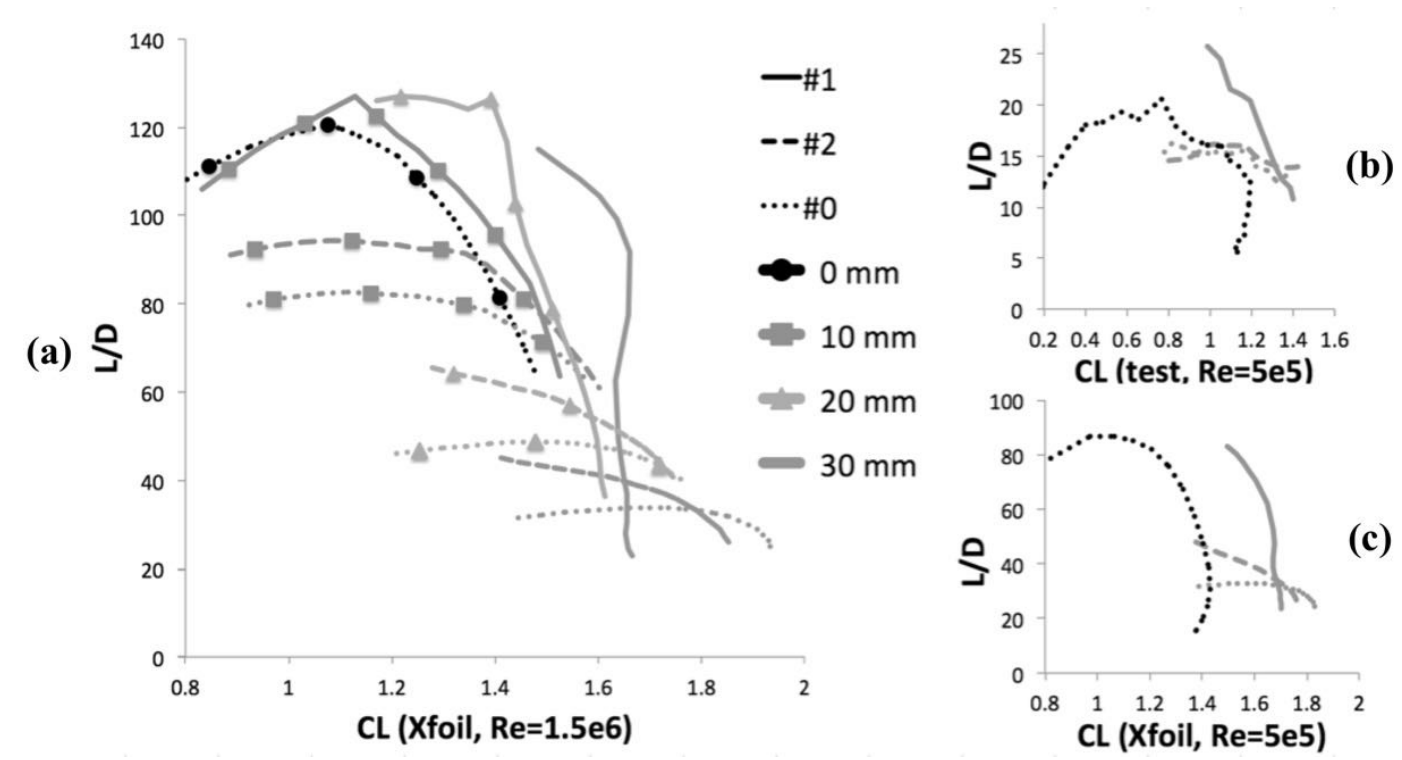

Figure 7. L/D - $C_{L}$ curves of aerofoils with increased camber and different trailing edge deflections, showing morphing strategies outperforming hinged aerofoil (dotted lines) and outperforming each other at different $C_{\mathrm{L}}$ range, all aerofoils except the baseline have $0^{\circ} \sim 10^{\circ}$ angle of attack.

(a)
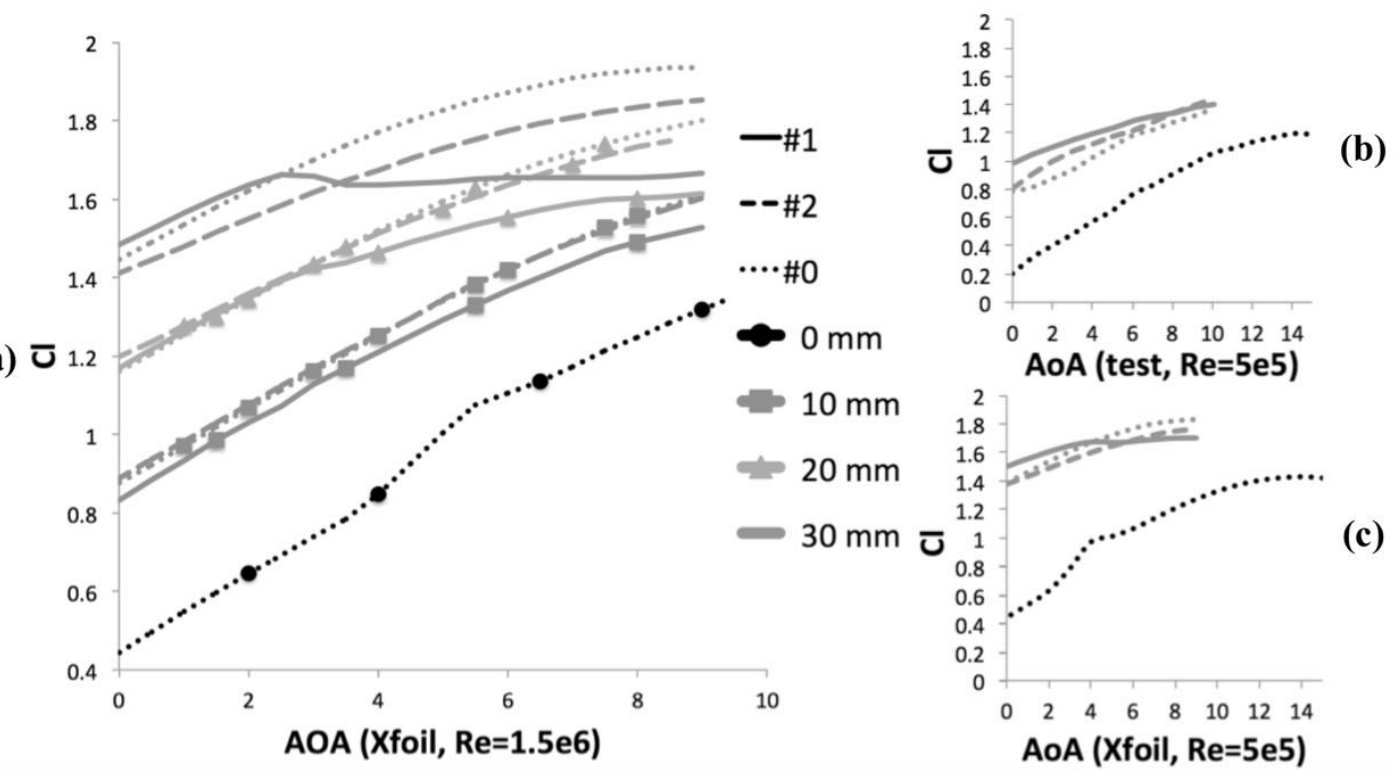

Figure 8. Lift curves of aerofoils with increased camber and different trailing edge deflections, showing that the strategies with the highest efficiency in Figure 7 lose lift at relatively low angle of attack. 


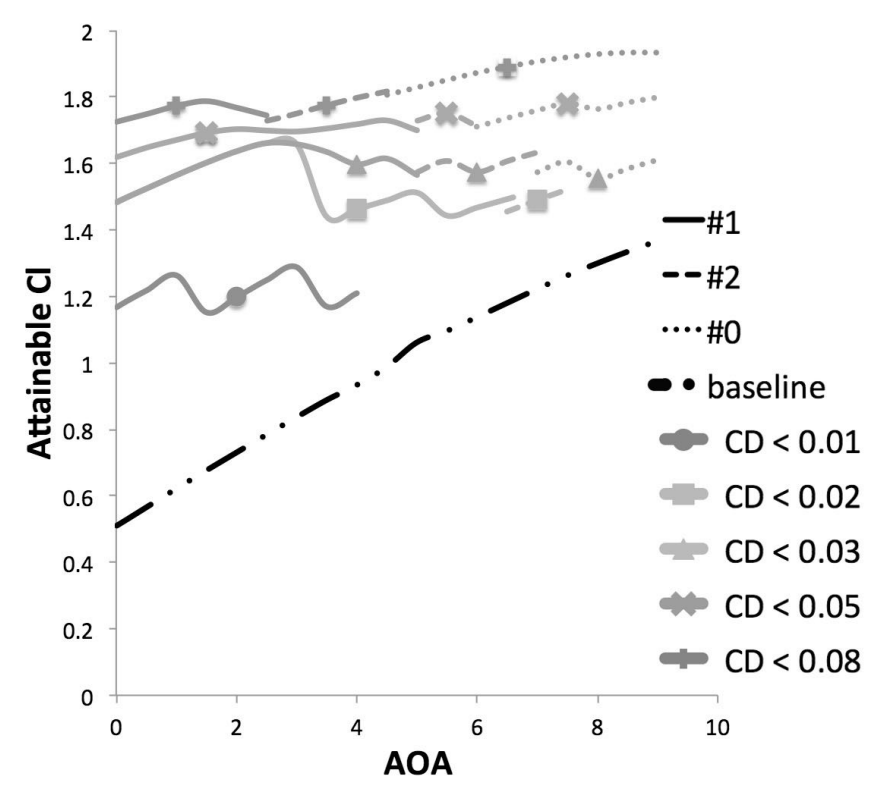

Figure 9. Attainable $C_{L}$ by three morphing strategies with varied $C_{D}$ values, generated by Xfoil analysis.

The reason why strategy 1 is efficient only at low angles of attack and suffers from low $\mathrm{C}_{\mathrm{Lmax}}$, while strategy 0 (the hinged flap) is the most efficient at high angles of attack can be explained in terms of flow separation. Flow separation occurs when the speed of the boundary layer decreases to zero under an adverse pressure gradient. Figure 10 shows the pressure coefficient $\left(\mathrm{C}_{\mathrm{P}}\right)$ across aerofoil with unit chord length at $6^{\circ}$ angle of attack using an inviscid analysis (where the flow always stays attached to show the complete pressure gradient), as well as the separation point predictions from analysis with viscous effect (where the flow separates in trailing edge region). Focusing on the region with $\mathrm{x} \approx 0.6 \sim 0.8$ on the upper surface where flow separation starts, strategy 1 (aerofoil with intensively increased camber near the maximum thickness) forms relatively uniform variation in curvature, and therefore, consistently increasing adverse pressure gradient 
that the boundary later cannot overcome, thus the flow separates early in this region and causes excessive drag. Strategy 0 (hinged aerofoil) forms intensively curved surface near the hinge, where a favourable pressure gradient is formed, thus the flow accelerates in this region and separation is delayed to the hinged point. The behaviour of strategy 2 (aerofoil with maximum camber increment near trailing edge) is between the other two.

Therefore, the efficiency of different strategies can be explained: although strategy 1 (aerofoil with maximum camber increment near leading edge) is the most efficient at low angles of attack, when the location of maximum camber increment moves towards trailing edge, the flow separation points also move towards trailing edge and lead to a higher lift and a lower drag at high angles of attack. 
To be noted, the hinge pivot of strategy 0 (hinged aerofoil) is located at $75 \%$ chord length, but in Figure 10 the hinge point is near $80 \%$ since the flap is deflected so the horizontal length of the flap is reduced. The three aerofoils have very similar chord length after morphing, and are normalized to unit chord length for illustration.

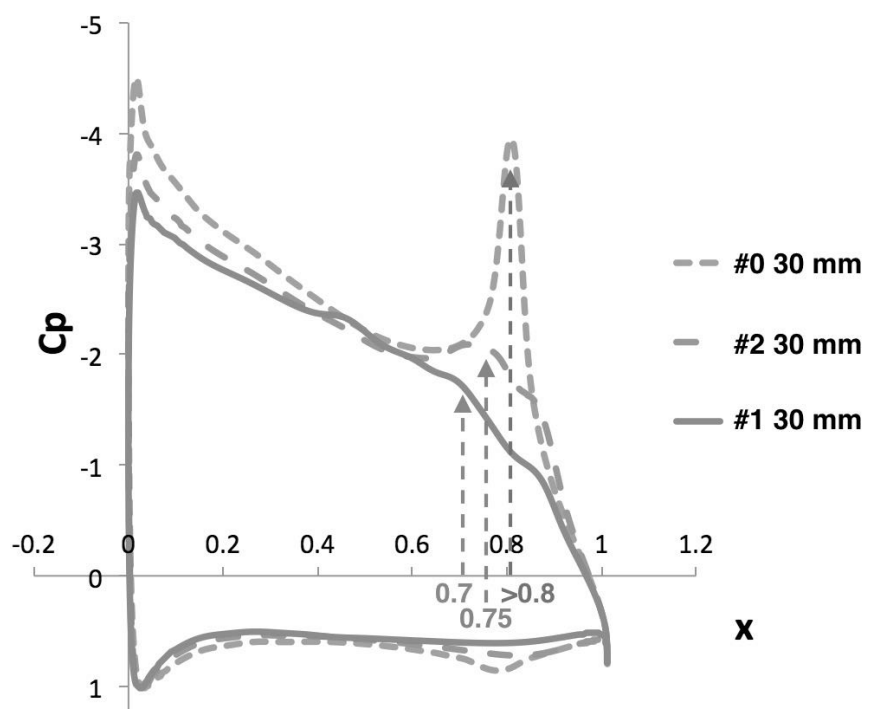

Figure 10. $C_{\mathrm{P}-\mathrm{x}}(\mathrm{x}=$ location along chord from leading edge) curve of aerofoils with $30 \mathrm{~mm}$ downward trailing edge deflection via different morphing strategies generated by inviscid analysis, and flow separation point predicted by viscous analysis.

\subsubsection{Results on Aerofoils with a Decreased Camber}

Aerofoils with decreased camber can generate low or negative lift for high-speed flight or manoeuvre and control pitching moment coefficient for manoeuvre or trimming.

As discussed in $§ 3.3 .1$, the key conclusions from the analysis are supported by the wind tunnel tests, so only test data are presented in this section for a clear illustration (see Figure 11). 
Since the reflexion of camber line near trailing edge let these aerofoils generate less or negative lift in the trailing edge region, the pitching moment $\mathrm{C}_{\mathrm{m}}$ is increased, and the increment is related to the camber line shape. Therefore, as shown by Figure 11, strategies 1 and 2 yield different near-zero or positive $C_{m}$. Meanwhile, similar to 3.3.1, strategies 1 and 2 yield similar $C_{\mathrm{L}}$ since they have the same trailing edge deflection. Thus it is possible to control pitching moment while maintaining constant $\mathrm{C}_{\mathrm{L}}$ by moving the location of maximum camber change towards trailing edge. However, drag penalty exists according to the $C_{D}$ curves, but it is considerably lower than a hinged flap.

As an example of the pitching moment control independent of $\mathrm{C}_{\mathrm{L}}$, according the $\mathrm{C}_{\mathrm{m}}$ curves in Figure 11, a $\mathrm{C}_{\mathrm{m}}$ increment of approximately 0.04 can be induced by changing the morphing strategy from strategy 1 to 2 , while the $C_{L}$ and $C_{D}$ curves are barely changed.

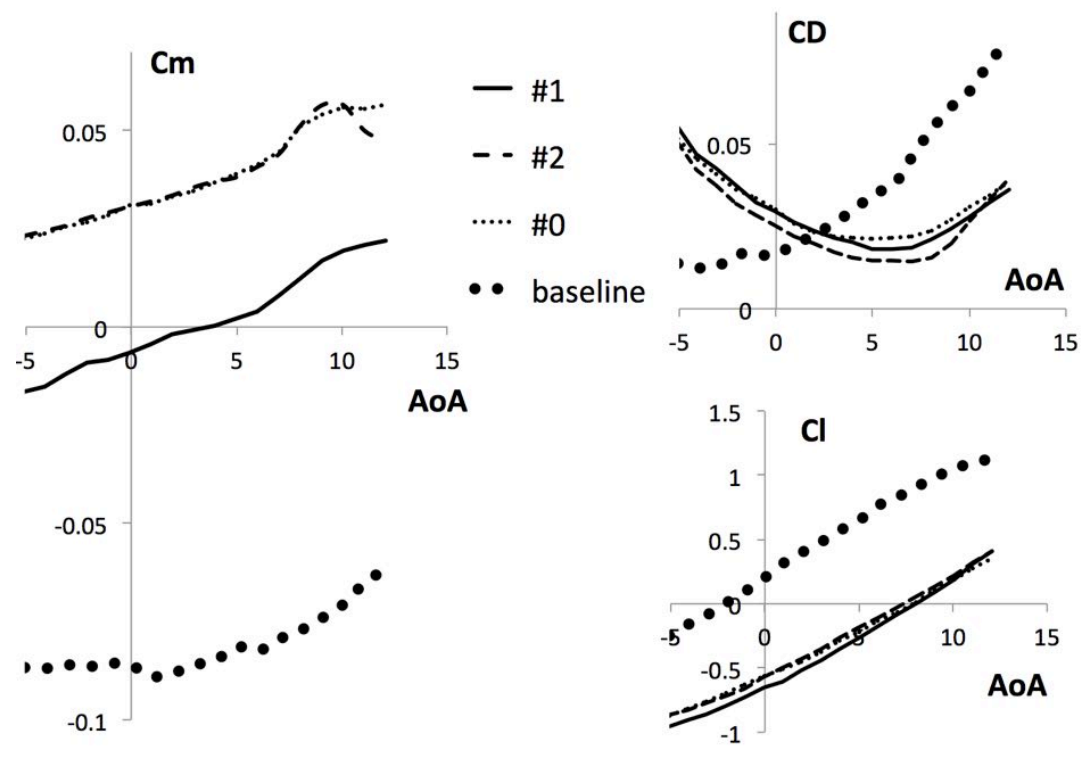

Figure 11. $C_{m} C_{D}$ and $C_{L}$ versus AoA of aerofoils with decreased camber and $20 \mathrm{~mm}$ trailing edge deflections, showing changes in $C_{m}$ independent of $C_{1}$ with little penalty in $C_{D}$. 


\section{Prototyping}

To further understand the behaviour of the morphing aerofoil, two prototypes are made, including a static prototype aiming to validate the loading capacity, and a moveable prototype aiming to test the morphing mechanism.

The static prototype is similar to the simulation model, but with some minor differences in materials. 3D printed nylon reinforced by CFRP plates is used in some parts. Since no change is made in the compliant structures including the trusses and the upper skin and runners, which are still made of CFRP, the mechanical behaviour of the prototype should be very similar to the simulation results. In addition, all the hinges are made of composite panel with Kevlar fibre and cyanoacrylate matrix (super-glue). The matrix along the hinge line is cracked to allow free rotation with negligible rotational resistance, and this is similar to the simulated condition. The prototype also includes a 3D printed wing box, which is over-designed to sustain the load from static loading test without inducing perceptible deformation. The finished morphing trailing edge weights $0.22 \mathrm{~N}$, which is close to the simulation prediction.

The static loading test is carried out with $26 \mathrm{~N}$ and $22 \mathrm{~N}$ load applied in the way identical to the simulation, which corresponds to the overall load of $70 \mathrm{~N}$ and $60 \mathrm{~N}$ across the whole aerofoil. The bonding between several hinges and upper skin fails under the load 
of $70 \mathrm{~N}$. But under the load of $60 \mathrm{~N}$, no failure is observed, and a trailing edge deflection of $0.2 \pm 0.1 \mathrm{~mm}$ is induced, which is close to the simulation prediction shown in Table 2 . However, the out-of-plane deflection of upper skin is larger than prediction due to excessive initial deflection induced by manufacture defects.

The moveable prototype (Figure 12) is similar to the static prototype, but the runner diameter is reduced from $1 \mathrm{~mm}$ to $0.8 \mathrm{~mm}$ to reduce the bending stiffness and therefore, the resistance to morphing. The trailing edge and the second truss from leading edge are each driven by one digital servo through 5 runners. Those runners slide through the lower joint of the truss elements while having one end fixed to the truss that is driven by it and the other end connected to a servo, thus the conditions are equivalent to a LUSM driven structure and the only difference is the actuators' location. According to simple analysis, it will provide the same actuation capacity (could support $250 \mathrm{~N}$ overall static load while inducing $<1 \mathrm{~mm}$ out-of-plane deflection) and $40 \%$ of the out-of-plane loading capacity in comparison with the static prototype, while the bending resistance of rods is also reduced to $40 \%$.

As no off-the-shelf LUSMs can be integrated into this small demonstrator, servos are used instead of LUSMs. This also provides a practical way to drive the presented morphing structure using conventional actuators before the development of LUSM could offer a viable solution. The moveable prototype has two servos as actuators, and therefore, two 
controlled degrees of freedom. The servos are controlled by two PWM signals generated from a STC80C516RD microcontroller. The morphed shapes are shown in Figure 12.

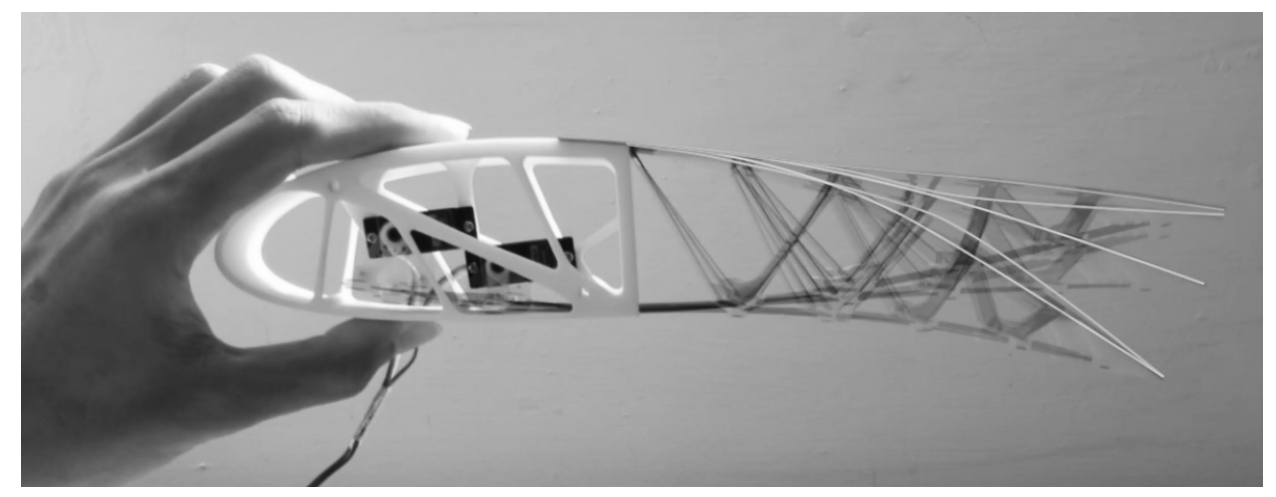

(a)

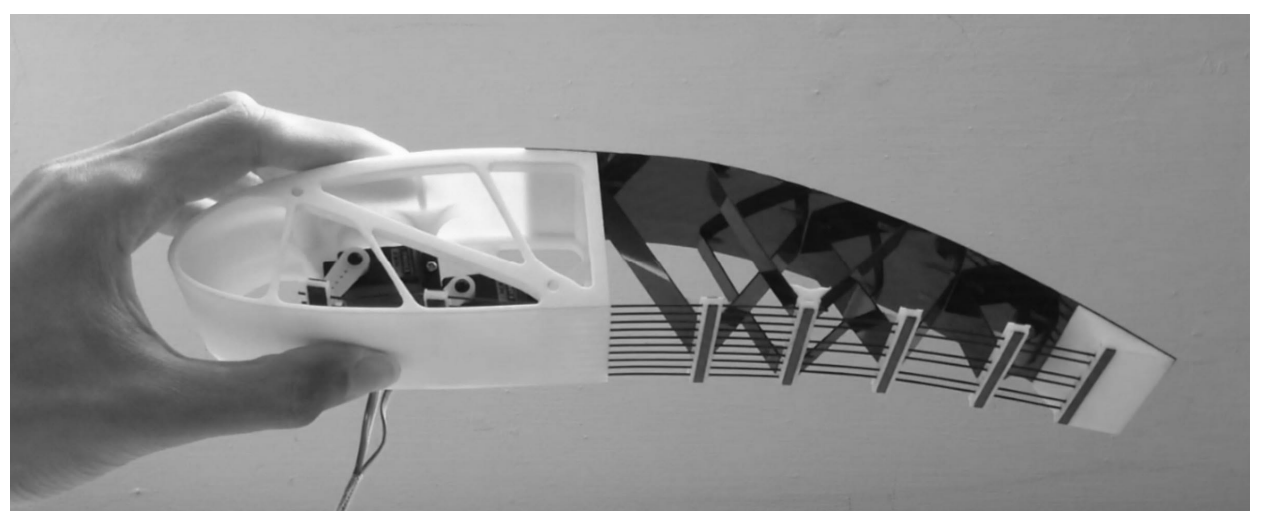

(b)

Figure 12. Moveable prototype, (a) side view showing five different morphing states, (b) oblique view showing the runners are connected to either the trailing edge or the second truss from the left.

It should be noted that at this stage both of the prototypes do not have morphing skin on the lower surface. This will not have significant influence on the tests since the skin has a minor effect on morphing or strength. The morphing skin will affect the flow and will require further examination in the near future. As an example, the segmented 
morphing lower skin shown in Figure 13 could be introduced; it consists of two overlapping skins that are bonded to the rigid wing box and the trailing edge, respectively. The rear skin bonded to the trailing edge can slide along the runners and above the skin part that is attached to the wing box.

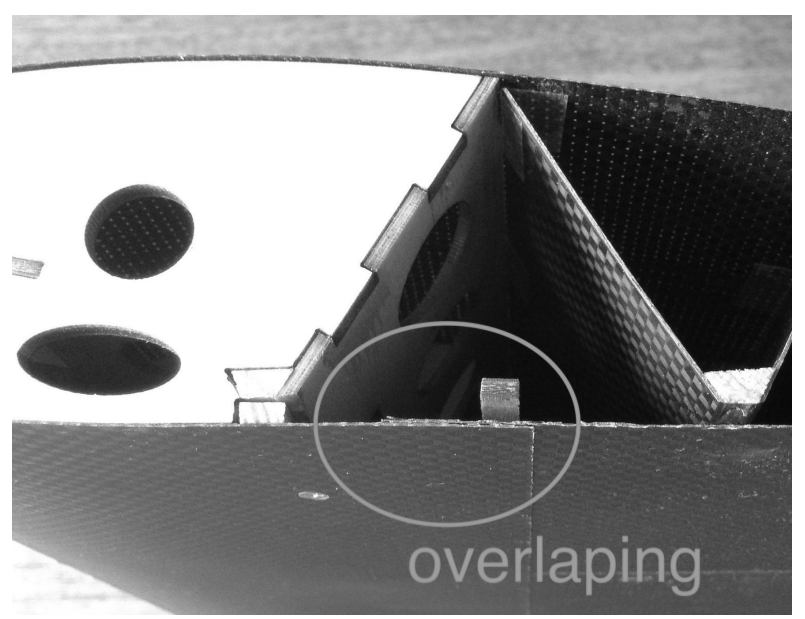

Figure 13. An example of an overlapping segmented bottom morphing skin that can be utilised to form an airtight aerofoil and transfer the aerodynamic load

\section{Conclusions}

In this paper, a new morphing aerofoil design concept, which combines compliant runners driven by linear ultrasonic motors (LUSM) with an innovative morphing structure with compliant composite truss, is presented. It is shown to offer fully controlled multiple degree-of-freedoms that provide multiple morphing configurations. 
The compliant truss structure has shown satisfactory specific loading capacity in both static finite element simulation and actual static loading test. The prototype morphing trailing edge section with a $50 \mathrm{~mm}$ span, a $160 \mathrm{~mm}$ chordwise length and a $0.22 \mathrm{~N}$ weight can support a $22 \mathrm{~N}$ load with a trailing edge deflection of $0.2 \mathrm{~mm}$.

To validate the aerodynamic benefit of multiple degrees of freedom, the aerodynamic analysis is compared with the wind tunnel test data. It is demonstrated that when the aerofoil camber is increased, all morphing states show a higher L/D ratio than a conventional hinged control surface at most flight conditions except at very high angles of attack. It is also shown that different morphing strategies outperform the others at different angles of attack. For example, at large angles of attack, the aerofoil aerodynamic efficiency can be further optimised by adapting morphing strategies according to current flight condition, i.e. by moving the location of the maximum camber increment along the aerofoil chord. Furthermore, the pitching moment can be controlled independently from $\mathrm{C}_{\mathrm{L}}$ and with little drag penalty; this is achieved by adapting different morphing strategies.

\section{References}

1. Kota S, Osborn R, Ervin G, Maric D, Flick P, Paul D. Mission adaptive compliant wing-design, fabrication and flight test. Morphing Vehicles, In RTO Applied Vehicle Technology Panel (AVT) Symposium. RTO-MP-AVT-168. Apr 2009. 
2. Barbarino S, Bilgen O, Ajaj RM, Friswell MI, Inman DJ. A Review of Morphing Aircraft. Journal of Intelligent Material Systems and Structures. 22(9). pp 823-77. Aug 2011.

3. Thill C, Etches J, Bond I, Potter K, Weaver P. Morphing skins. The Aeronautical Journal. 112(1129). pp 117-39. Mar 2008.

4. Campanile LF, Sachau D. The Belt-Rib Concept: A Structronic Approach to Variable Camber. Journal of Intelligent Material Systems and Structures. 11(3). pp 215-24. Mar 2000.

5. Campanile LF, Anders S. Aerodynamic and aeroelastic amplification in adaptive belt-rib airfoils. Aerospace Science and Technology. 9(1). pp 55-63. Jan 2005.

6. Kota S, Hetrick JA, Osborn R, Paul D, Pendleton E, Flick P, et al. Design and application of compliant mechanisms for morphing aircraft structures. In: Proceedings of SPIE Smart Structures and Materials 2003. 5054. pp 24-33. Aug 2003.

7. Woods BK, Bilgen 0, Friswell MI. Wind tunnel testing of the fish bone active camber morphing concept. Journal of Intelligent Material Systems and Structures. 25(7). pp 772-85. Apr 2014.

8. Schroeder TA, Wayman CM. The two-way shape memory effect and other "training" phenomena in $\mathrm{Cu}-\mathrm{Zn}$ single crystals. Scripta Metallurgica. 11(3). pp 225-30. Mar 1977.

9. Trease B, Kota S. Design of Adaptive and Controllable Compliant Systems With Embedded Actuators and Sensors. Journal of Mechanical Design. 131(11). 111001. Oct 2009.

10. Rediniotis OK, Wilson LN, Lagoudas DC, Khan MM. Development of a Shape-Memory-Alloy Actuated Biomimetic Hydrofoil. Journal of Intelligent Materials Systems and Structures. 13(1). pp 35-49. Jan 2002.

11. Georges T, Brailovski V, Morellon E, Coutu D, Terriault P. Design of shape memory alloy actuators for morphing laminar wing with flexible extrados. Journal of Mechanical Design. 131(9):091006. Sep 2009.

12. Koreanschi A, Gabor OŞ, Ayrault T, Botez RM, Mamou M, Mebarki Y. Numerical Optimization and Experimental Testing of a Morphing Wing with Aileron System. In: 24th AIAA/AHS Adaptive Structures Conference (p. 1083). 2016. 
13. Gabor OŞ, Koreanschi A, Botez RM, Mamou M, Mebarki Y. Numerical simulation and wind tunnel tests investigation and validation of a morphing wing-tip demonstrator aerodynamic performance. Aerospace Science and Technology. 53:136-53. Jun 2016.

14. Gabor OS, Koreanschi A, Botez RM. Optimization of an Unmanned Aerial System'wing using a flexible skin morphing wing. SAE International Journal of Aerospace. 6(2013-01-2095):115-21. Sep 2013.

15. Gabor OS, Simon A, Koreanschi A, Botez RM. Aerodynamic performance improvement of the UAS-S4 Éhecatl morphing airfoil using novel optimization techniques. Proceedings of the Institution of Mechanical Engineers, Part G: Journal of Aerospace Engineering. 230(7):1164-80. Jun 2016.

16. Gabor OŞ, Simon A, Koreanschi A, Botez RM. Improving the UAS-S4 Éhecal airfoil high angles-of-attack performance characteristics using a morphing wing approach. Proceedings of the Institution of Mechanical Engineers, Part G: Journal of Aerospace Engineering. p.0954410015587725. May 2015.

17. Smith RC. Smart Material Systems: Model Development. Society for Industrial and Applied Mathematics. Philadelphia. 2005.

18. Lockyer AJ, Martin CA, Lindner DK, Walia PS, Carpenter BF. Power Systems and Requirements for Integration of Smart Structures into Aircraft. Journal of Intelligent Materials Systems and Structures. 15(4). pp 305-15. Apr 2004.

19. Tieck RM, Mohanchandra KP, Carman GP. Smart material actuators for airfoil morphing applications. In: Proceedings of SPIE Smart Structures and Materials 2004. 5390. pp 235-246. Jul 2004.

20. Bartley-Cho JD, Wang DP, Martin CA, Kudva JN, West MN. Development of High-rate, Adaptive Trailing Edge Control Surface for the Smart Wing Phase 2 Wind Tunnel Model. Journal of Intelligent Materials Systems and Structures. 15(4). pp 279-91. Apr 2004.

21. Jacobs, Eastman N. Airfoil section characteristics as affected by protuberances. 1934.

22. Mack S, Brehm C, Heine B, Kurz A, Fasel HF. Experimental investigation of separation and separation control on a laminar airfoil. In4th AIAA Flow Control Conference (pp. 23-26). Jun 2008. 
23. Gross A, Fasel HF. Numerical investigation of separation for airfoils at low Reynolds numbers. In40th Fluid Dynamics Conference and Exhibit 2010 Jun (p. 4736). Jun 2010.

24. Koreanschi, A., Sugar-Gabor, O. and Botez, R.M., Numerical and Experimental Validation of a Morphed Wing Geometry Using Price-Païdoussis Wind Tunnel Testing.

25. Giguere $\mathrm{P}$, Selig MS. Freestream velocity corrections for two-dimensional testing with splitter plates. AIAA Journal. 35(7). pp 1195-1200. Jul 1997.

26. Pankhurst RC, Holder DW. Wind-tunnel technique: an account of experimental methods in low-and high-speed wind tunnels. Pitman. Bath. 1952.

27. Abbott IH, Albert E. Von Doenhoff, Louis S. Stivers Jr. Summary of airfoil data. National Advisory Commitee for Aeronautics. Report; 1945.

28. Wolken-Möhlmann G, Knebel P, Barth S, Peinke J. Dynamic lift measurements on a FX79W151A airfoil via pressure distribution on the wind tunnel walls. Journal of Physics: Conference Series. 75(1). 012026. Jul 2007. 